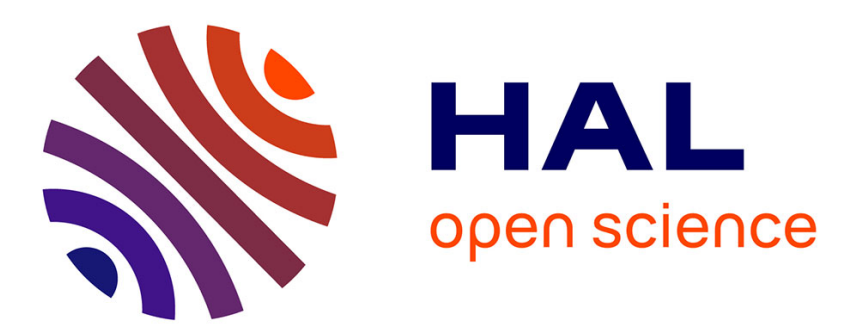

\title{
A simple method to analyse non-cohesive sediment mobility in coastal environment
}

Déborah Idier, Emmanuel Romieu, Rodrigo Pedreros, Carlos Oliveros

\section{To cite this version:}

Déborah Idier, Emmanuel Romieu, Rodrigo Pedreros, Carlos Oliveros. A simple method to analyse non-cohesive sediment mobility in coastal environment. Continental Shelf Research, 2010, 30, pp.365377. 10.1016/j.csr.2009.12.006 . hal-00509800

\section{HAL Id: hal-00509800 https: / hal-brgm.archives-ouvertes.fr/hal-00509800}

Submitted on 16 Aug 2010

HAL is a multi-disciplinary open access archive for the deposit and dissemination of scientific research documents, whether they are published or not. The documents may come from teaching and research institutions in France or abroad, or from public or private research centers.
L'archive ouverte pluridisciplinaire HAL, est destinée au dépôt et à la diffusion de documents scientifiques de niveau recherche, publiés ou non, émanant des établissements d'enseignement et de recherche français ou étrangers, des laboratoires publics ou privés. 
Provided for non-commercial research and education use. Not for reproduction, distribution or commercial use.

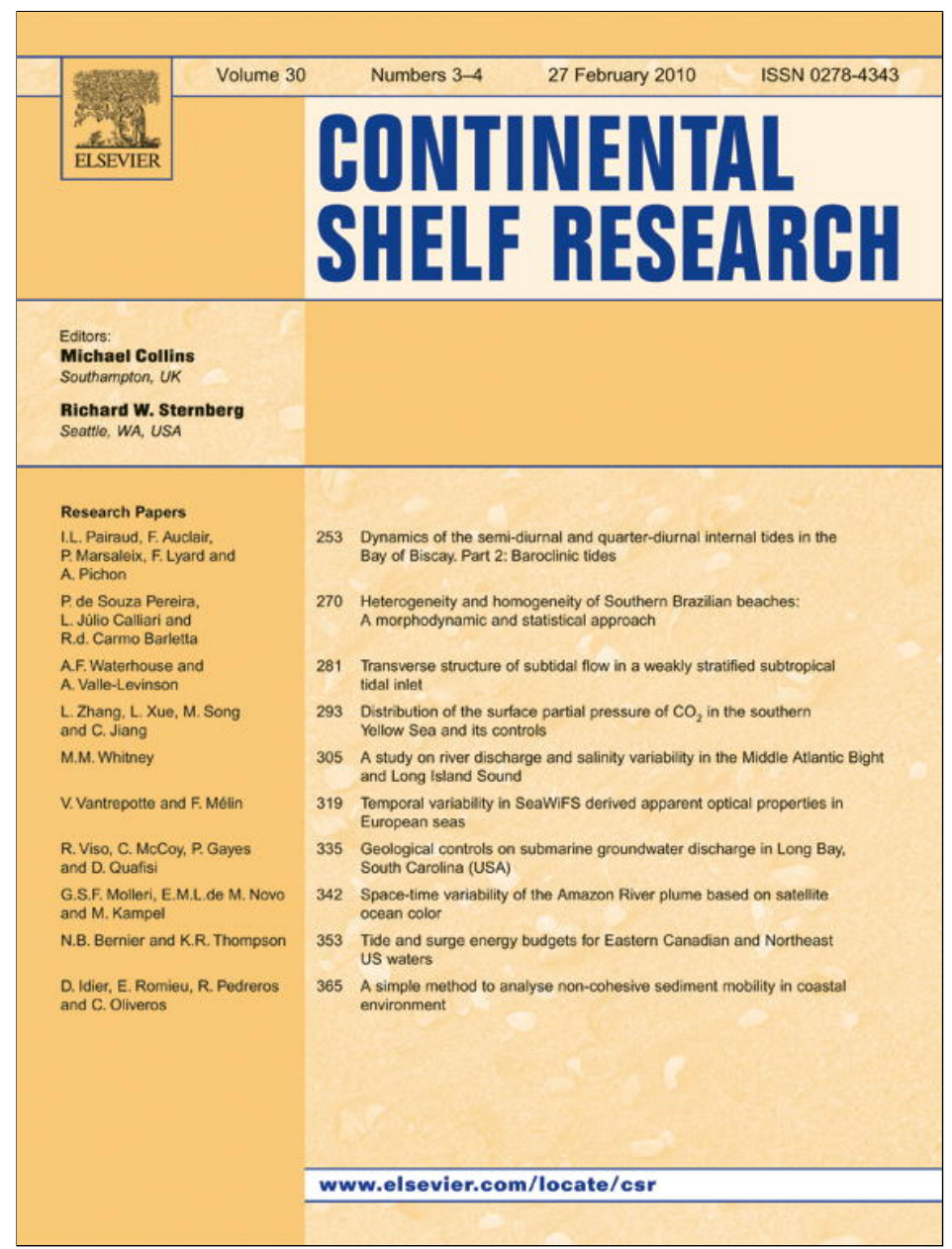

This article appeared in a journal published by Elsevier. The attached copy is furnished to the author for internal non-commercial research and education use, including for instruction at the authors institution and sharing with colleagues.

Other uses, including reproduction and distribution, or selling or licensing copies, or posting to personal, institutional or third party websites are prohibited.

In most cases authors are permitted to post their version of the article (e.g. in Word or Tex form) to their personal website or institutional repository. Authors requiring further information regarding Elsevier's archiving and manuscript policies are encouraged to visit:

http://www.elsevier.com/copyright 


\title{
A simple method to analyse non-cohesive sediment mobility in coastal environment
}

\author{
Déborah Idier* , Emmanuel Romieu, Rodrigo Pedreros, Carlos Oliveros \\ BRGM - Service RNSC - 3, avenue C. Guillemin - 45060 Orléans cedex 2, France
}

\section{A R T I C L E I N F O}

\section{Article history:}

Received 5 August 2009

Received in revised form

1 December 2009

Accepted 16 December 2009

Available online 4 January 2010

Keywords:

Current

Waves

Continental shelf

Sediment mobility

Modelling

Pertuis Charentais region

\begin{abstract}
A B S T R A C T
This paper presents a method to investigate the relative influence of waves, wind-induced currents and tidal currents on sediment mobility in coastal environment. It is based on the assumption that, knowing high uncertainties linked to sediment dynamics studies, simple sediment mobility indicators are sufficient tools to provide useful information. This method is based on five main steps: (1) assessing hydrodynamic conditions and related errors spatially and temporally for an area; (2) evaluating the bottom shear stress induced by these hydrodynamic conditions; (3) providing simple sediment mobility indicators; (4) analysing the sensitivity of these indicators to the existing hydrodynamic uncertainties; (5) interpreting indicators knowing their limits (identified in the sensitivity analysis). This methodology is applied to a test site on the inner shelf, seaward of the Pertuis Charentais region in France. Using wave (SWAN) and sea-level and currents (MARS-2DH) modelling, we study the spatial distribution of the relative contribution of waves, tides and wind-induced current in the non-cohesive sediment mobility under storm conditions. The deduced sediment dynamics indicators reveal the dominant action of waves in sediment initiation in the offshore area, in water depths of up to $60 \mathrm{~m}$. The sensitivity study, performed in order to evaluate the validity of results, shows that the sediment mobility indicators still provide relevant information, even for hydrodynamic uncertainties of $\pm 20 \%$ or furthermore when only a qualitative sedimentological knowledge of the area is available.
\end{abstract}

(c) 2009 Elsevier Ltd. All rights reserved.

\section{Introduction}

The continental shelf, especially its internal part, undergoes the action of currents and waves. The analysis of sediment transport processes requires estimating the relative influence of each of these two processes. It is still often assumed that waves have no influence on sediment dynamics in waters deeper than $20 \mathrm{~m}$, although many local observations have highlighted waveinduced sediment mobility at greater depth (e.g., $80 \mathrm{~m}$ in Drake and Cacchione, 1985 and $23 \mathrm{~m}$ in Idier et al., 2006).

A complete comparative study of the different factors contributing to sediment transport must cover a wide spatial extent and a long period of time and quantify the sediment dynamics phenomenon. The use of hydrodynamic models has already provided large amounts of quantitative information on extensive areas, using a variety of bedload formulae to quantify sediment dynamics by transport fluxes or suspended sediment concentrations (e.g. Harris and Wiberg, 2002). However, many authors have stressed the limitations inherent to the use of deterministic bedload formulae, which estimate transport rate with an error factor of at least 2 (e.g. Van Rijn, 1993; Eidsvik,

\footnotetext{
* Corresponding author. Tel.:+33238643568; fax: +33238643399.

E-mail address: d.idier@brgm.fr (D. Idier).
}

2004; Pinto et al., 2006). Therefore, for a simple comparative study, other ways to derive sediment dynamics information from hydrodynamic knowledge could be explored. Dufois et al. (2008) compared wave and current-induced bottom shear stress distribution to the actual sediment cover in the Gulf of Lions shelf. Other sedimentology studies tried to link the spatial distribution of wave-induced bottom shear stress to the water depth at which the sand-mud transition occurs (George and Hill, 2008). Following these approaches, we propose in this article to present a further analysis of the bed shear stress distribution by computing it into different sediment dynamics indicators linked to the associated grain size which could be set in motion. This approach of focusing mainly on sediment motion initiation and the duration for which the sediment is set in motion is quite widely used in engineering applications to study the impact of sediment clapping or dredging on a single area. The study's objective is to use and extend this type of method to quantify the relative influence of waves, windinduced currents and tidal currents on sediment mobility in a macro-tidal environment, over an extended shallow continental shelf area (from open sea to protected areas) and for a period including different hydrodynamic conditions (mainly storm conditions).

Thus, a specific methodology is presented, which aims to spatially represent this influence of the hydrodynamic 
components on non-cohesive sediment mobility. Models of waves and currents are called on for the purpose. Hydrodynamic model results are converted into sediment dynamics information following a quite basic but useful methodology proposed by Idier et al. (2006).

In order to ensure the relevance of the proposed methodology, it is applied to a case study involving the inner shelf seaward of France's Pertuis Charentais region. The choice of this study area is based on two reasons: on the one hand the application of the methodology in this area highlights its relevance by complementing existing local studies; on the other hand results can be compared between past studies and this one, in order to validate the methodology.

First, the overall methodology is described. Then, after a general presentation of the study area and the existing local studies, a detailed description of the set-up and validation of the models is given. Finally, the sediment mobility results are presented and discussed.

\section{Methodology for studying sediment mobility}

\subsection{Overview of the method}

The study's main aim is to propose a simple method that can be used to obtain a spatial and temporal analysis of the sediment mobility induced by hydrodynamics, in an extended area. A major issue for such sediment dynamics studies is overcoming the different sources of uncertainties liable to affect the final results. As stated earlier, the quantification of fluxes involves errors of a factor of 2 or more, and which may even be much higher yet if wave-driven transport is considered (Pinto et al., 2006). Actually, the use of sediment transport formulae involves both statistical and epistemic uncertainties. Indeed, all sediment transport formulae are highly sensitive to hydrodynamic and sediment grain-size errors (Pinto et al., 2006). Furthermore, faced with the complexity of sediment movement, one is obliged to choose among many different formulae and subsequently perform many case-specific calibrations, and the process imposes many limitations on the results.

In this study, our intention is to devise a method that strives to limit uncertainties on the results by reducing the complexity of results used for interpretation. The idea is to call on the simplest sediment dynamics indicators still able to be significant even when the knowledge of hydrodynamic conditions or sediment cover is imperfect.

Therefore, instead of evaluating sediment transport completely, the method only quantifies the bottom shear stress induced by hydrodynamics. This bottom shear stress, expressed in $\mathrm{N} / \mathrm{m}^{2}$, can be directly translated into a simple sediment mobility indicator which is the maximum grain size that can be set in motion by this stress. At this stage, many uncertainties have already been propagated (Paphitis, 2001); however, this indicator is far less complex than quantifying sediment fluxes while applying transport formulae: a new level of complexity is introduced thereby increasing uncertainties. This study will demonstrate that the simple use of this maximum grain size set in motion can provide useful information through different indicators directly related to it, especially when applied to an extensive area and over different hydrodynamic conditions.

The main steps involved in this method are: (1) assessing hydrodynamic conditions and related errors spatially and temporally for an area; (2) evaluating the bottom shear stress induced by these hydrodynamic conditions; (3) providing simple sediment mobility indicators; (4) conducting a sensitivity analysis to ensure the significance of indicators in light of existing uncertainties; (5) interpreting indicators knowing their limits (identified in the sensitivity analysis).

\subsection{The use of hydrodynamic models}

Two hydrodynamic models serve to reproduce wave characteristics and tidal and wind-induced currents at quite a large scale $(\sim 100 * 100 \mathrm{~km})$ : (1) the shallow-water model called MARS-2DH, that solves the Saint-Venant equations (Lazure and Dumas, 2008) for tidal and wind-induced currents and (2) the third-generation SWAN wave model using finite difference methods for wave characteristics (Booij et al., 2004).

When this process is applied at the scale of the Pertuis area, the final resolutions of the models are $200 \mathrm{~m}$ for MARS-2DH and $300 \mathrm{~m}$ for SWAN, and we focus on sediment mobility outside the surf zone (e.g. for water deeper than about $5 \mathrm{~m}$ ). This implies that phenomena like wave-induced currents, undertow and longshore drift are not considered. Validation is achieved using hydrodynamic measurements performed in November 2002 (Idier et al., 2006).

These two models provide information for bed shear stress computation. The outputs of the shallow-water model MARS used to compute the sediment mobility are water depth and depth integrated current magnitude, whereas the SWAN wave model outputs used are the peak period and the bottom orbital velocity.

\subsection{Sediment motion initiation}

In order to set sediment particles in motion, bed shear stress must exceed a critical value. To estimate the maximum size of the grains able to be set in motion by waves and currents, we use the Shields parameter for the sediment motion of grains having a size $d$ :

$$
\theta=\frac{\tau_{b}}{g\left(\rho_{s}-\rho\right) d}
$$

where $\tau_{b}\left(\mathrm{~N} / \mathrm{m}^{2}\right)$ is the hydrodynamic bed shear stress, $g$ the gravity acceleration, $\rho$ the water density and $\rho_{s}$ the sediment density. This stress can be caused by the currents (hydrodynamic shear at the bottom due to the currents $\tau_{b, c}$ ), or the waves (stress at the bottom due to waves, averaged on a half-wave cycle $\left.\tau_{b, w}\right)$. Following Van Rijn (1993), the value of the stress $\tau_{b, c w}$ applied to the bottom under the joint action of waves and currents, integrated over a half-wave period, can be written:

$\left|\tau_{b, c w}\right|=\alpha_{r}\left|\tau_{b, c}\right|+\left|\tau_{b, w}\right|$

with $\alpha_{r}$, the bed shear stress reduction coefficient $(\leq 1)$, which is less than 1 for large waves combined with weak currents. This coefficient is mainly related to the apparent roughness and the bed roughness. To estimate this coefficient, it is necessary to know the apparent roughness and the boundary-layer thickness. $\alpha_{r}$ is considerably smaller than one in case of relatively high waves combined with a weak current, whereas $\alpha_{r}=1$ means that we neglect the current velocity reduction in the near bed region, which is due to wave-current interaction. Thus $\alpha_{r}=1$ implies that the total bed shear stress is potentially overestimated. A comparative study (Van Rijn, 1993) shows that the errors associated to this simplification are quite negligible for wave and current in the same direction, whereas the maximal error $(\mathrm{O}(10 \%))$ occur for waves perpendicular to the current. Thus, as a first approach, we use $\alpha_{r}=1$, which seems reasonable in view of the fact that the tidal currents are quite large in the study area.

Based on the estimation of bed shear stress using the Shields parameter, we deduce the maximum size of grains which are set in motion. For motion initiation, only the skin-related bed shear stresses have to be considered (Van Rijn, 1993). Furthermore, the 
study domain is restricted to the non-cohesive sediments $\left(d_{50}>0.063 \mathrm{~mm}\right)$. Thus, in the figures (e.g. Fig. 6), the area of cohesive sediment is hatched, and corresponding results will not be discussed even though values are given in the figures.

\subsection{Bed shear stress}

The wave-related bed shear stress $\left(\tau_{b, w}\right)$, averaged over a halfwave cycle, can be written (Van Rijn, 1993):

$\tau_{b, w}=0.25 \rho f_{w}\left(\hat{u}_{b}\right)^{2}$

with $\hat{u}_{b}$ the peak value of the near-bed orbital velocity, based on linear theory. Coefficient $f_{w}$ is the wave friction (Swart, 1976), which is a function of bed roughness $k_{s}$ and the peak value of the orbital excursion $\hat{A}_{\delta}\left(\hat{A}_{\delta}\right.$ being related to the peak value of the orbital velocity and the peak period):

$\left\{\begin{array}{c}f_{w}=\exp \left(-6+5.2\left(\hat{A}_{\delta} / k_{s}\right)^{-0.19}\right) \text { for } \hat{A}_{\delta} / k_{s}>1.57 \\ f_{w}=0.3 \text { for } \hat{A}_{\delta} / k_{s} \leq 1.57\end{array}\right.$

The model outputs used to compute sediment mobility are the peak period and the orbital velocity, for every node at every model time step. The current related bed shear stress can be written:

$\tau_{b, c}=\rho g U^{2} /\left(K h^{1 / 6}\right)^{2}$

$U(\mathrm{~m} / \mathrm{s})$ is the norm of the horizontal depth averaged velocity, $K$ is the Strickler friction coefficient, and $h(\mathrm{~m})$ is the water depth. The Strickler coefficient is also related to the bed roughness coefficient $k_{s}$ :

$K=18 \log \left(\frac{12 h}{k_{s}}\right) h^{-1 / 6}$

The outputs of the MARS shallow-water model used to compute sediment mobility are the water depth and current magnitude, for every node and model time step (re-sampled hourly for the study).

\subsection{Sediment dynamics indicators}

With the purpose to translate bed shear stress into simple sediment-mobility information, whilst endeavouring to hold down uncertainties we propose two indicators: (1) the maximal grain size which can be set in motion and (2) the time duration $T_{d}$ (percentage of the simulated period) during which the critical bed shear stress of the chosen grain size is exceeded by the bed shear stress. This second indicator is called the mobility of the grain size $D g$. These two indicators are directly related on the studied period.

For each of the following configurations, there are two main parameters: (1) the chosen grain size $D g$ considered and (2) the chosen bed roughness $k s$, the most sensitive parameter when computing bed shear stress. Bed roughness may refer to grain roughness $\left(k s=3^{*} D g\right)$ or to bed roughness induced by ripples.

Hereinafter, the reference case will correspond to a reference grain size of $0.2 \mathrm{~mm}$ ( $k s$ value of $0.6 \mathrm{~mm}$ ), as this is representative of medium sand.

\section{The November 2002 case study}

\subsection{The study area}

The study site (Fig. 1a) encompasses the area lying between the Pertuis of Maumusson, to the south, and the coast of Sables d'Olonne, to the north, and between the Sables d'Olonne to the west and the continent to the east.

\subsubsection{Hydrodynamic and sediment cover description}

Based on the tidal current atlas (SHOM), the depth-averaged tidal currents are about $0.5 \mathrm{~m} / \mathrm{s}$ and the tidal range is $5.1 \mathrm{~m}$ for a mean spring tide in the inter-island area. Bertin et al. (2008) described the wave climate in twelve representative wave classes, using model results (NWW3 model, Tolman, 2002) at an offshore location $\left(2.5^{\circ} \mathrm{W} ; 46^{\circ} \mathrm{N}\right)$. Annual classifications between 1997 and 2005 allowed them to distinguish two main swell categories within offshore wave classes: (1) low to moderate WNW swell conditions, representing 28-69\% of the annual wave climate (depending on the year) and where $H s=0.8-2.5 \mathrm{~m}, \mathrm{Tp}=6-12 \mathrm{~s}$ and Dirp $=274-292^{\circ} \mathrm{N}$; (2) energetic W swell conditions, representing $15-27 \%$ of the annual wave climate (depending on the year) and where $H s=2.5-9.4 \mathrm{~m}, T p=11-15 \mathrm{~s}$ and Dirp $=265-280^{\circ} \mathrm{N}$. Category (1) swells occur mostly during summer months (June-September), while category (2) occur mostly during winter months (November-March), spring and autumn being characterised by a transition between these two wave regimes. These observations demonstrate that this area undergoes a macro-tidal regime and a high energy wave climate with strong seasonal variations.

As to sedimentary characteristics (Fig. 1b), and from a schematic point of view, moving seaward from the mainland, one first encounters mud flats between the continent and the islands up to the northernmost part of the study area. Next, along the western coast of the islands, some bedrock areas occur. Finally, further offshore, seabed sediment is mainly composed of sands and gravely sands (for the external part), except offshore to the south-west of Oléron Island, where there is a large mud deposit.

\subsubsection{Existing knowledge on the study area}

The theoretical relative impact of waves and currents on the sediments of the Bay of Biscay shelf has already been investigated (Barthe and Castaing, 1989) using both hydrodynamic measurements and the abacus of the sediment motion initiation. Furthermore, the influence of tidal currents, swells, wind waves, and residual currents has been studied by Idier et al. (2006) on the basis of measurements at a single location between the islands of Oléron and Ré (Fig. 1a, location S4), in the so-called Pertuis Charentais area. They show that, for an area $23 \mathrm{~m}$ deep at this location S4, swells (rather than wind waves) are energetic enough to initiate the motion of sands, which are then transported by the currents. Sands with a grain size of $0.2 \mathrm{~mm}$ would be transported during $92 \%$ of the field measurement duration ( $\sim 3$ weeks in November 2002), whereas gravels would be only sporadically set in motion, especially during conjunctions of storms and spring tides.

Complementary to these local studies based on hydrodynamic measurements, hydrodynamic modelling approaches have been used on the Pertuis Charentais area. Tidal currents have been studied on various scales ranging from that of the Maumusson inlet (Fig. 1a) (Bertin et al., 2005) up to the scale of the Pertuis (the part between the islands and the continent) and the islands (Fig. 1a) (Stanisière et al., 2006; Chaumillon et al., 2008). Some studies have also focused on the influence of waves on the Saint Trojan beach on the western coast of Oléron Island (Fig. 1a) (Bertin et al., 2008).

However, these studies were mainly conducted at a local scale or focused on hydrodynamics alone and few large-scale studies have been devoted to the relative influence of currents and waves on sediment dynamics. The application of the described methodology on this area will extend spatially the understanding of this influence of hydrodynamic components, while being able to validate it thanks to this existing knowledge. 
a

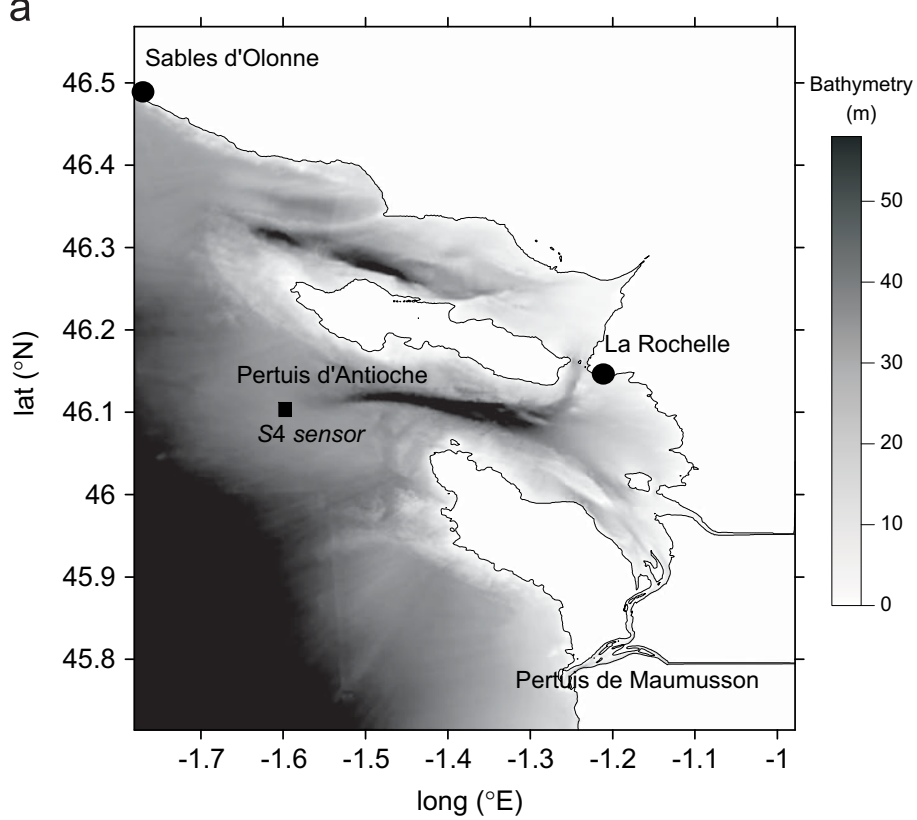

b

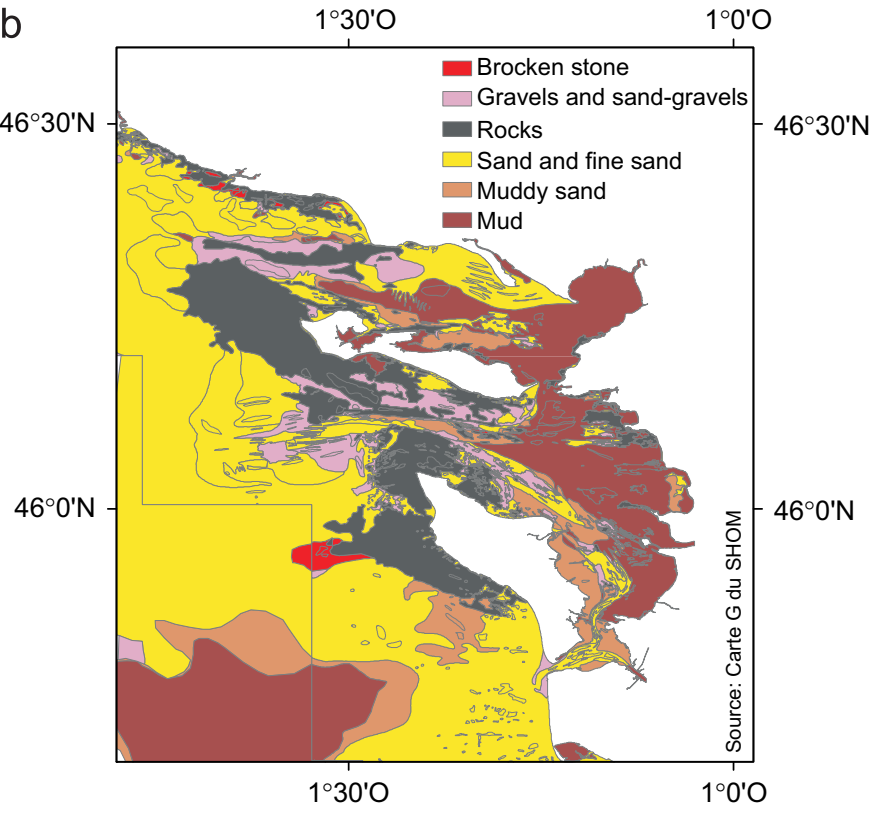

Fig. 1. The study area and the position of current meter S4. (a) Bathymetry (the bathymetric data were provided by SHOM, GEBCO and IFREMER) and (b) Sedimentology (from SHOM, 2000).

\subsection{The study period}

The results presented by Idier et al. (2006) were obtained for the period between 5 and 27 November 2002, chosen for the modelling study presented in this paper. Three main storm events occurred on 7, 13-14 and 20-21 November, with wind velocities reaching $15-20 \mathrm{~m} / \mathrm{s}$ on northern Oléron Island. During the last storm event period, at point S4 (Fig. 1a), a significant wave height of $6 \mathrm{~m}$ was reached for a peak period of $18 \mathrm{~s}$ (Fig. 3, Idier et al., 2006). This storm event is associated with the second swell category described by Bertin et al. (2007) (see Section 3.1), but with a longer period. Furthermore, regarding wave statistics in this area (Anemoc 2007, point coast 2697), such waves with heights significantly greater than $6 \mathrm{~m}$ occur approximately eight days a year (autumn-winter). Thus, the period studied is representative of a significant stormy autumn-winter context.

\section{Model set up and validation}

\subsection{Wave modelling}

\subsubsection{Description and set-up}

Wave modelling is based on the use of the third-generation SWAN wave model using finite difference methods and developed by Delft University (NL). The evolution of the wave spectra is described by the wave action conservation equation (Booij et al., 2004). In order to model the study area, we call on two nested models (Fig. 2), with grid sizes of $1 \mathrm{~km}$ (B0) and $300 \mathrm{~m}$ (B1). The bathymetric data we use come from the GEBCO database and SHOM and Ifremer bathymetric data. As to the boundary conditions, four nodes of the NWW3 model (Tolman, 2002) are used, yielding triplets (significant wave height, peak period and peak direction) on the western edge of the B0 box (Fig. 2). From Bidlot (2008), the scatter index (rms error standardised with mean observed data) for the October-November 2002 wave data ranges between $10 \%$ and $11 \%$ for the significant wave height and $20 \%$ and 26\% for the peak period (NWW3 data). Meteorological conditions are taken into account over the whole area covered by

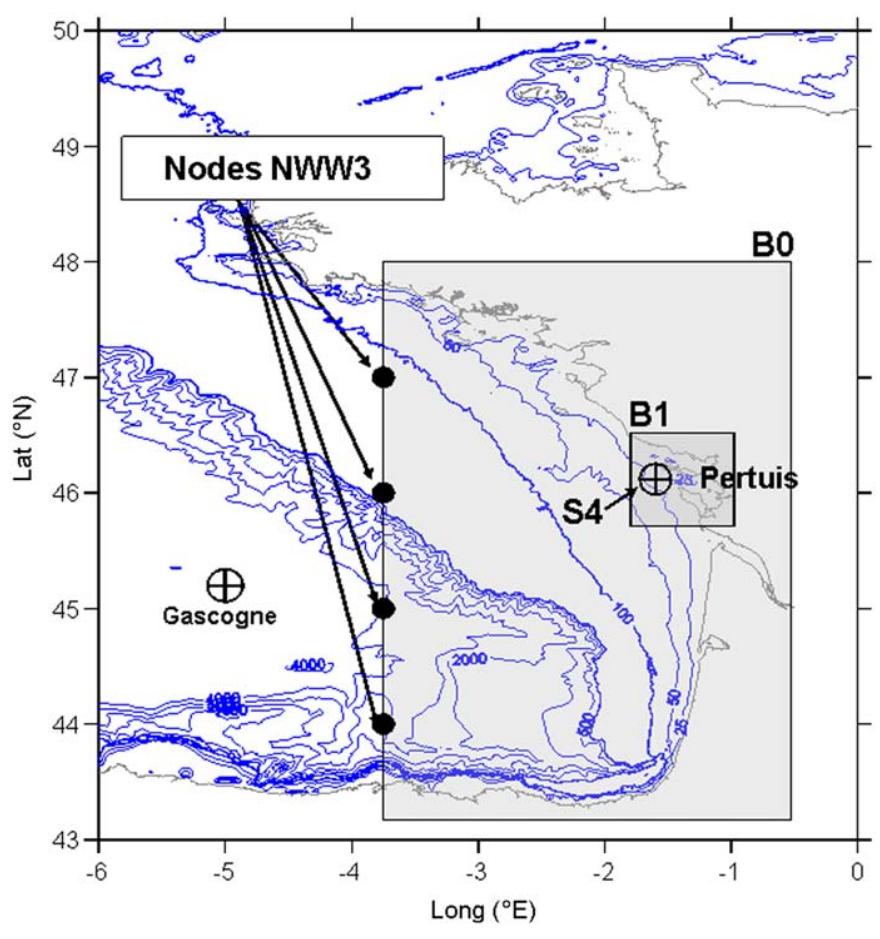

Fig. 2. Computational domains of the nested boxes ( $\mathrm{B} 0$ and $\mathrm{B} 1$ ) for the wave model.

the B0 box using Global Forecast System (GFS, developed by NCEP-NOAA) outputs. The reference sea level in the SWAN computations is the tidal level at the La Rochelle harbour (SHOM tidal prediction).

\subsubsection{Validation}

The model was validated using measurements made at the S4 point location in November 2002 (Fig. 1a). Fig. 3 shows that wind 

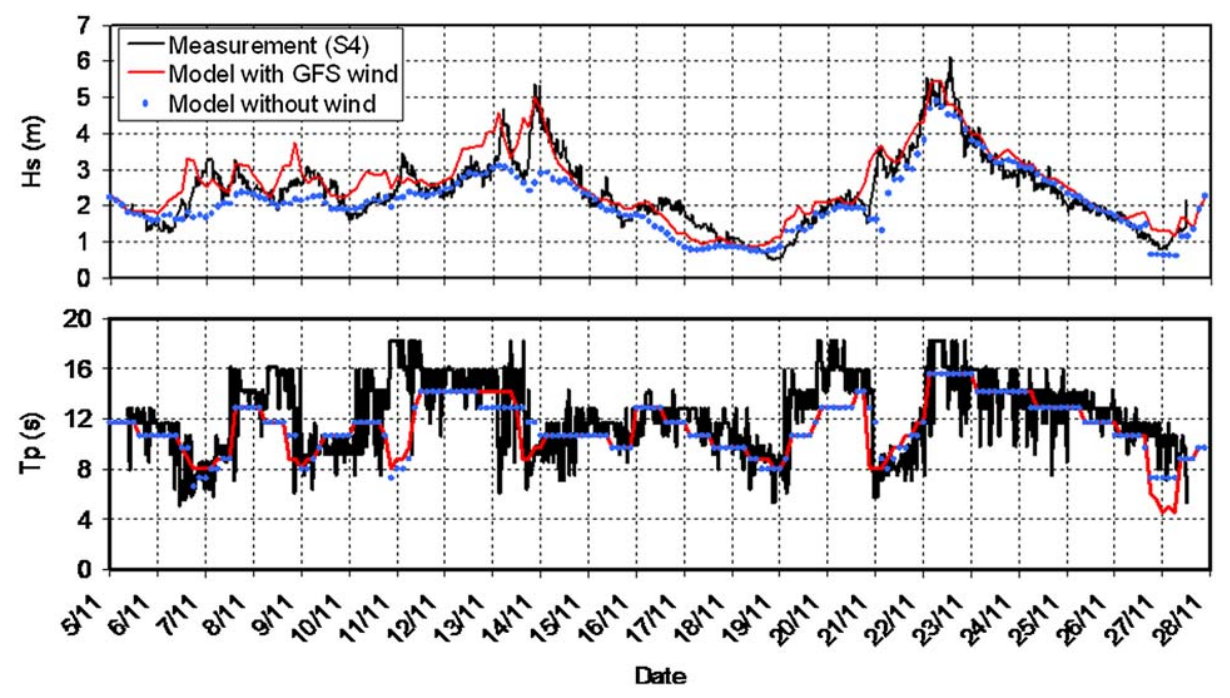

Fig. 3. Wave results (significant wave height and peak period): measurement and model at the S4 location.

effect in the B0 box must be taken into account in the simulations. Indeed, ignoring wind effect results in underestimating wave height by a factor of up to 2 (e.g. 14 November 2002). When wind velocity is taken into consideration, reasonably good agreement is obtained between the observations and the model (Fig. 3), with a correlation coefficient $R^{2}$ of 0.81 . The scatter index (SI) is about $21 \%$ for the significant wave height and $31 \%$ for the peak period. These errors come from boundary conditions errors (see Section 4.1.1) and from the model itself. However, the indicators used for the analysis conducted below are particularly sensitive to energetic waves. Thus, it is worthwhile to estimate errors for these energetic waves. The scatter index SI is equal to $9 \%$ (resp. $14 \%$ ) for waves with $\mathrm{Hs}$ greater than $4 \mathrm{~m}$ (resp. $3 \mathrm{~m}$ ). These errors are quite reasonable and their influence on the sediment dynamics study is dealt in Section 6.1.

\subsection{Current modelling}

\subsubsection{Description and set-up}

To model the tidal and wind-induced currents, we implemented the shallow-water model called MARS-2DH (Saint-Venant equations) (Lazure and Dumas, 2008). This code, developed by Ifremer, is based on the finite difference method. Focusing on the bed shear stress magnitude, it should be noticed here that 2DH approaches have some limits regarding wind-induced bed shear stress. Indeed, as shown by Hall and Davies (2002), depending on the period and sense of rotation of the wind field, the wind effect extends over the entire water column (and thus, 2DH models should provide relevant bed shear stress) or the near surface layer (and then, 2DH model results are not relevant to provide bed shear stress). However, during storms, when wind forcing is quite large, the highly turbulent nature of the water column means that wind-induced current could be predicted using 2DH models (Jones and Davies, 2006). The present hydrodynamic modelling is done for this type of stormy conditions period.

The nested modelling technique is used, with a large box R0 (grid size: $5500 \mathrm{~m}$ ) covering the Bay of Biscay and the English Channel, down to a small box R3 (grid size: $200 \mathrm{~m}$ ) covering the area of the two islands, Ré and Oléron (Fig. 4). The bathymetric data used for this model are the same as those used for wave modelling (GEBCO, SHOM and some specific surveys made by Ifremer).

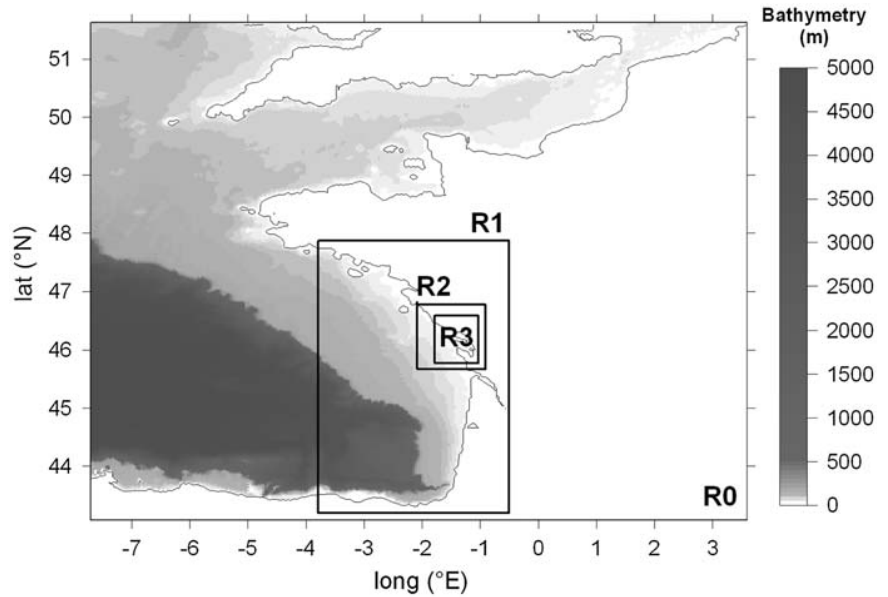

Fig. 4. Computational domains of the nested boxes (R0 to R3) for the shallowwater model MARS.

The boundary conditions are drawn from the FES2004 database (Lyard et al., 2006) which provides the 14 most important tidal components. Meteorological data are based on the GFS data at the node $\left(46^{\circ} \mathrm{N} ; 2.5^{\circ} \mathrm{W}\right)$. These wind conditions are supposed uniform over the entire area.

Nicolle and Karpytchev (2007) emphasized the need for spatially variable friction to represent tidal amplification and asymmetry in the area. They finally selected Chezy coefficients of $100 \mathrm{~m}^{0.5} \mathrm{~s}^{-1}$ for mud flats and $60 \mathrm{~m}^{0.5} \mathrm{~s}^{-1}$ elsewhere, corresponding to Strickler coefficients of 32 and $54 \mathrm{~m}^{1 / 3} \mathrm{~s}^{-1}$ in water $40 \mathrm{~m}$ deep. Nevertheless, our model was built with a uniform Strickler coefficient (Strickler friction parameterisation in MARS-2DH). This value was set at $40 \mathrm{~m}^{1 / 3} \mathrm{~s}^{-1}$ for the last box R3, as a result of model calibration and in accordance with Stanisière et al. (2006) and with the Chezy coefficients chosen by Nicolle and Karpytchev (2007). In the present study, the Strickler coefficient is uniform, and thus the model does not properly reproduce current asymmetry. However, errors induced for current intensity will be quantified, in order to investigate the sensitivity of final results to such errors. 


\subsubsection{Validation}

The hydrodynamic model was validated regarding its capacity to reproduce tidal dynamics (water level and currents). The model results have been compared to:

- The SHOM tidal water level predictions at the harbours of La Rochelle, Aix Island and Gatseau, for a mean spring tide (24 January 2004).

- The field measurements performed in November 2002, processed with the T-Tide toolbox (Pawlowicz et al., 2002) to extract the tidal components (Idier et al., 2006). The S4 velocity measurements are point data, so that processing is required prior to comparing it with 2DH model output (depth integrated current). The integrated velocity is obtained by fitting an assumed logarithmic profile in agreement with the von Karman-Prandtl theory. In order to calibrate the bed roughness $z 0$ parameter defining this profile, we used existing instantaneous ADCP profiles at the S4 location.

The validation of the tidal signal for two spring-neap tide cycles exhibits an rms error ranging from $0.09 \mathrm{~m}$ at La Rochelle to $0.17 \mathrm{~m}$ at Gatseau. The stronger error at Gatseau could be due to the quality of the bathymetric data in this area, where the seabed changes very quickly.

Qualitatively, at the S4 location in November 2002, the model reproduces the semi-diurnal oscillations and the amplitude variations of the water level and current, due to the tide (Figs. 5a-c). Mean phase errors, which are not negligible, play an important role in instantaneous rms errors calculation; they range from $11 \mathrm{~min}$ for water level signal to $1 \mathrm{~h}$ for current representation. However, the discrepancies between the model and the measurements in terms of water level and currents are comparable to the model errors cited in the literature for the same area (Stanisière et al., 2006):

- rms error of $0.18 \mathrm{~m}$ for the free surface level, to be compared to a mean tidal range of about $3 \mathrm{~m}$ during the campaign,

- rms error of $0.12 \mathrm{~m} / \mathrm{s}$ for the current magnitude, to be compared to the mean of the ebb/flood current amplitude of
$0.6 \mathrm{~m} / \mathrm{s}$ during the campaign. It can be noticed that peak velocity errors, which will have an important role in the analysis, are still in an acceptable range for the present study, with a SI of $23 \%$ for velocity magnitude larger than $0.6 \mathrm{~m} / \mathrm{s}$ ( $1 \%$ of observations), and a SI of $26 \%$ for velocity magnitude larger than $0.5 \mathrm{~m} / \mathrm{s}$ ( $5 \%$ of observations).

Regarding wind-induced hydrodynamics, the free surface level and the currents computed by the model are processed to extract the storm surge (total free surface level minus the tidal level) and the non-tidal (i.e. residual) currents (total current minus the tidal current). These processed results are compared to the processed S4 observations. Although the errors are quite large for the studied phenomena (rms error around $0.1 \mathrm{~m}$ ), storm surge tendencies are accurately reproduced by the model.

Thus, the hydrodynamic model yields acceptable results albeit with some errors. The influence of these errors on the sediment dynamics study is looked into in Section 6.1.

\section{Results for the reference case $(D g=0.2 \mathrm{~mm}$ and $k s=3 * 0.2 \mathrm{~mm}$ )}

\subsection{Maximum grain size set in motion}

The sizes of the grains set in motion (Fig. 6), based on modelling results at point S4, are somewhat different ( 39\%) from those estimated from hydrodynamic measurements (Idier et al., 2006). Indeed, as mentioned in this reference, the maximum grain size set in motion is mainly controlled by wave conditions as opposed to currents. Also, as shown in Section 4.1.2, errors on the wave height and peak period amount respectively to $21 \%$ and $31 \%$. This is mainly due to wave model output errors. Nevertheless we still use the model to extend the results obtained analysing the S4 measurements spatially and temporally (Idier et al., 2006), bearing in mind these limitations on the quality of the hydrodynamic model outputs. This point will be discussed later on.

Fig. 7a shows the maximum size of grains potentially set in motion for every node of the models, independently of the
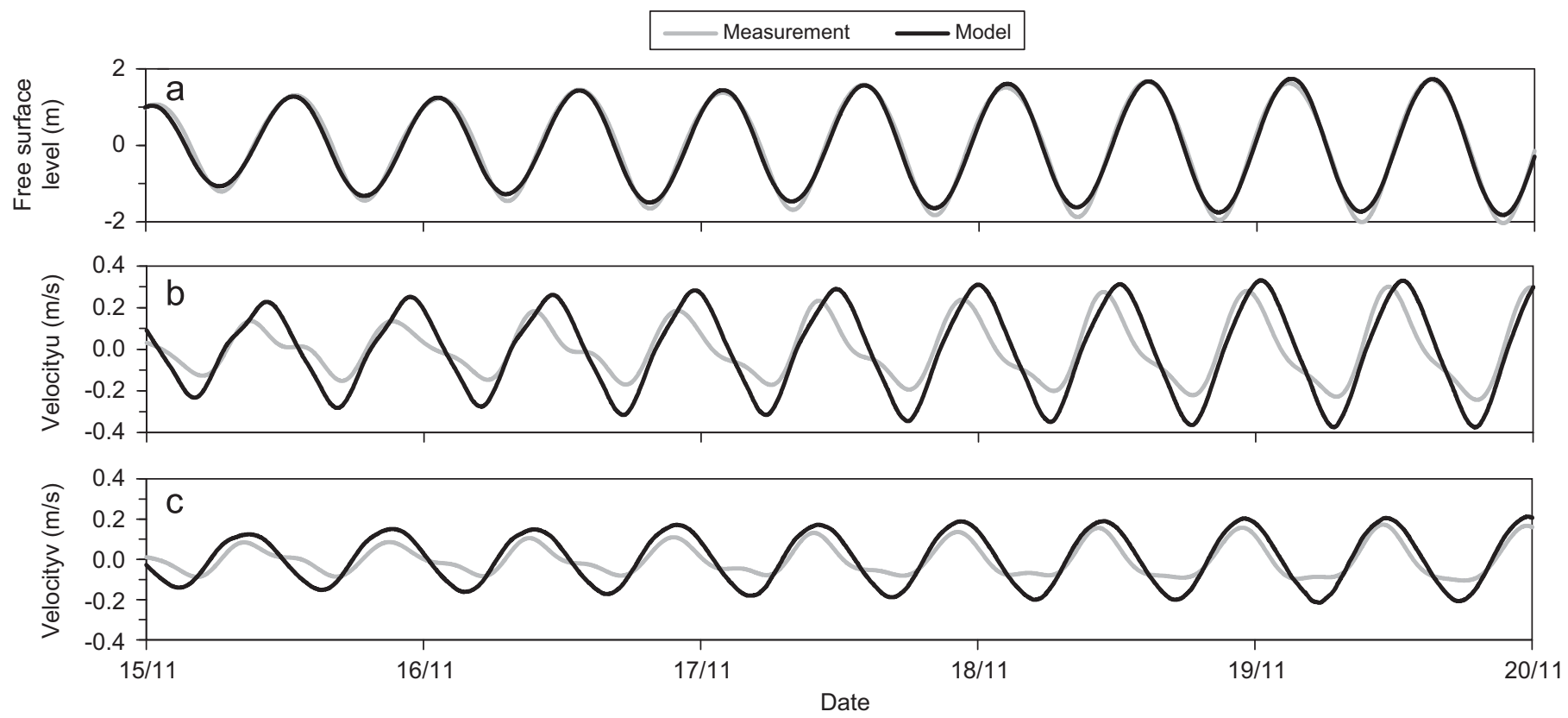

Fig. 5. Tidal hydrodynamics at the $S 4$ location: measurements and model results. (a) Tidal free surface level, (b) S-N tidal current (positive in the North direction), (c) E-W tidal current (positive in the West direction). 


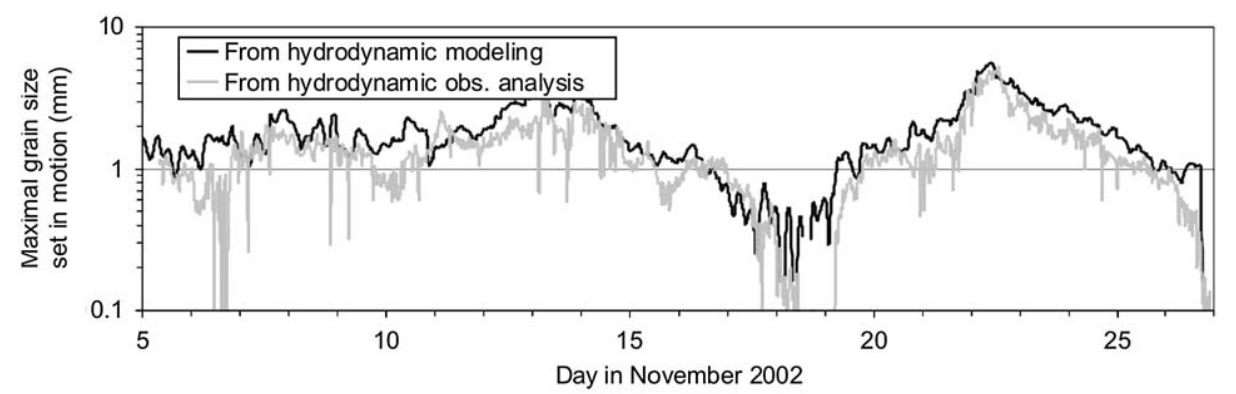

Fig. 6. Maximum grain size set in motion during the 5-27 November 2002 period.
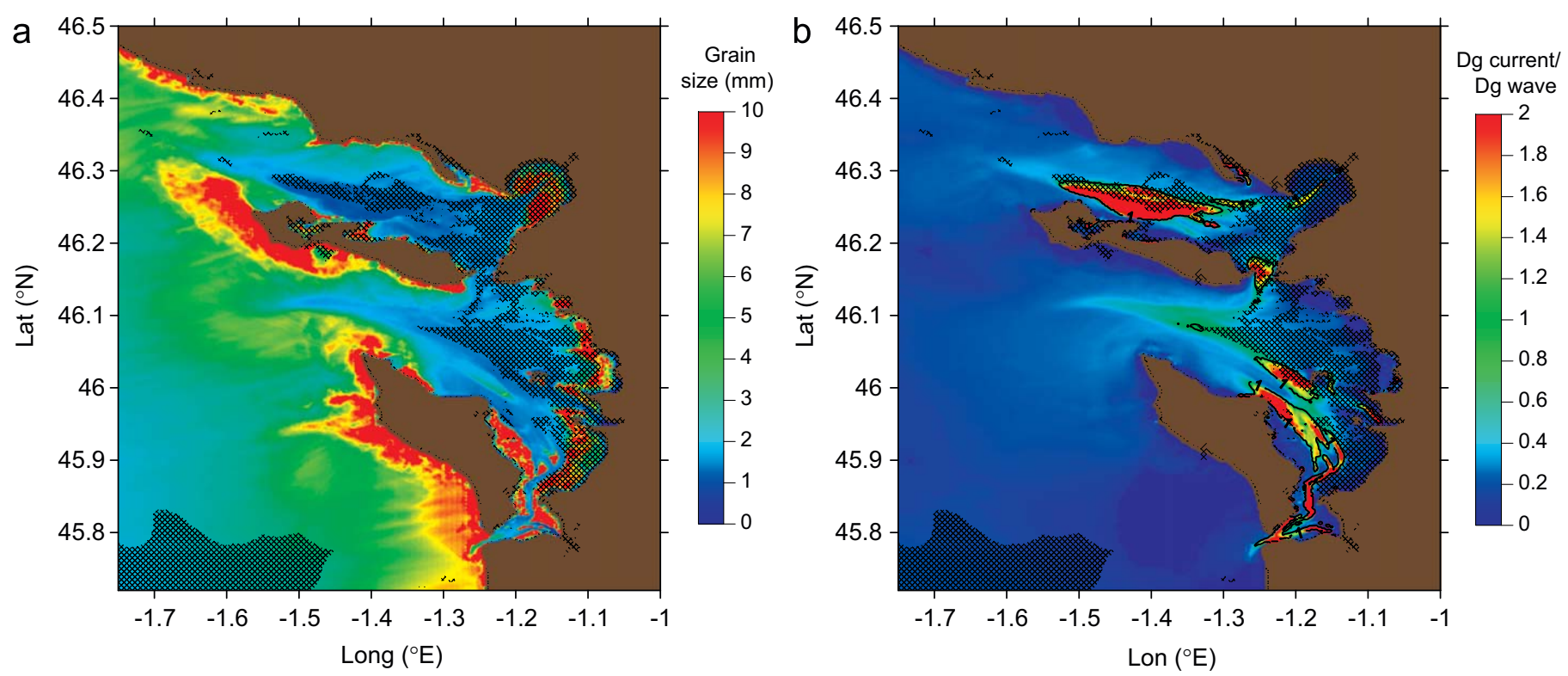

Fig. 7. Maximum grain size potentially set in motion for the 5-27 November 2002 period, by the combined action of wave and currents. (b) Ratio between the grain sizes potentially set in motion by the currents and that potentially set in motion by the waves. Areas of cohesive sediment areas are indicated by the hatchings.

sediment facies, assuming a bed roughness equal to the skin roughness for $0.2 \mathrm{~mm}$ sediments. The results show that the grains are mainly set in motion on the external part of the Pertuis, with grain sizes reaching $4 \mathrm{~mm}$ for a $30 \mathrm{~m}$ water depth and $10 \mathrm{~mm}$ along the western coasts of the islands. On the bays, the grain sizes set in motion are smaller, on the order of $0.5-3 \mathrm{~mm}$. Fig. $7 \mathrm{~b}$ shows that the sediment motion initiation, offshore, and along the western coast of the islands, is mainly due to waves, whereas, based on the model results, only the strong current area (the northern headland of Ré and Oléron islands, Pertuis Breton, Pertuis de Maumusson) are subject to significant sediment motion due to currents. Because most of these areas have little exposure to waves, only the current could have an effect on the initiation of sediment motion.

\subsection{The mobility of the reference grain size}

In order to estimate representative sediment mobility over the site area and the period studied, the relative durations of motion initiation of grains of $0.2 \mathrm{~mm}$ diameter are computed. According to Fig. 8a, these grains would be set in motion during $75 \%$ of the study period, across most of the area (the western coasts of islands). They would be more rarely set in motion $(\sim 50 \%)$ in the south-western part (40-50 m water depth) and less yet in the internal area of the Pertuis region (between the islands and the continent ( $<50 \%$ ). This is consistent with the results obtained for the maximum grain size potentially set in motion (Fig. 7a). Fig. 8b shows that waves, which are dominant on the external part of the area, would be responsible for motion initiation during most of the duration of the study period. Currents (Fig. 8c), which have a dominant action in the internal area, would account for a sediment motion only half as much of the time.

These results indicate that: (1) over most of the study area, sediment $D g=0.2 \mathrm{~mm}$ can be set in motion; (2) offshore of the islands, the sediment is set in motion $90 \%$ of the time-span of the campaign; (3) inside the bays, mobility is smaller, about $50 \%$ of the time; (4) at greater depth, in the south-west, sediment mobility occurs between $30 \%$ and $70 \%$ of the campaign duration. Thus, mobility in the studied area is quite pronounced for the selected representative grain size, at least for the study period, representative of a stormy autumnal climate.

\subsection{Identifying thresholds}

The results described above are ones integrated over the entire campaign period. In order to identify some thresholds in the hydrodynamic forcing (focusing on wave height, since it is the most sensitive parameter) above which the mobility increases rapidly, we integrate the results over space, rather than time. At any time, each spatially integrated value is calculated as the 

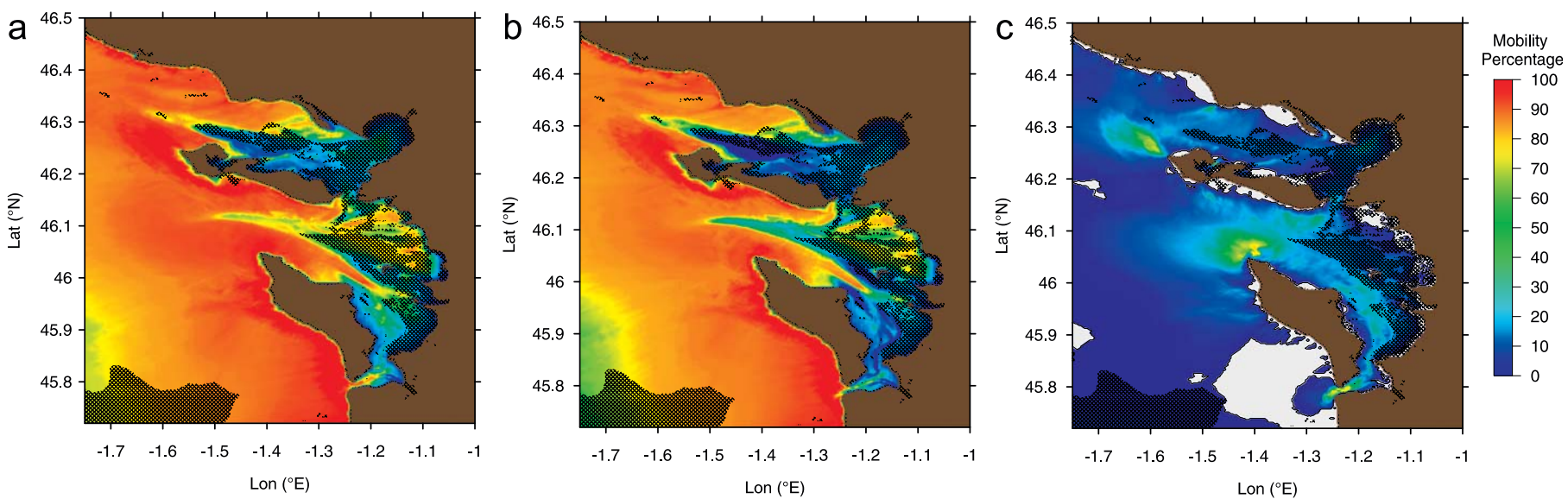

Fig. 8. Relative duration of motion initiation for $0.2 \mathrm{~mm}$ grains during the $5-27$ November 2002 period under the action of: (a) currents and waves, (b) waves and (c) currents. The light grey zone indicates the area where no mobility occurs. Cohesive sediment areas are indicated by the hatchings.
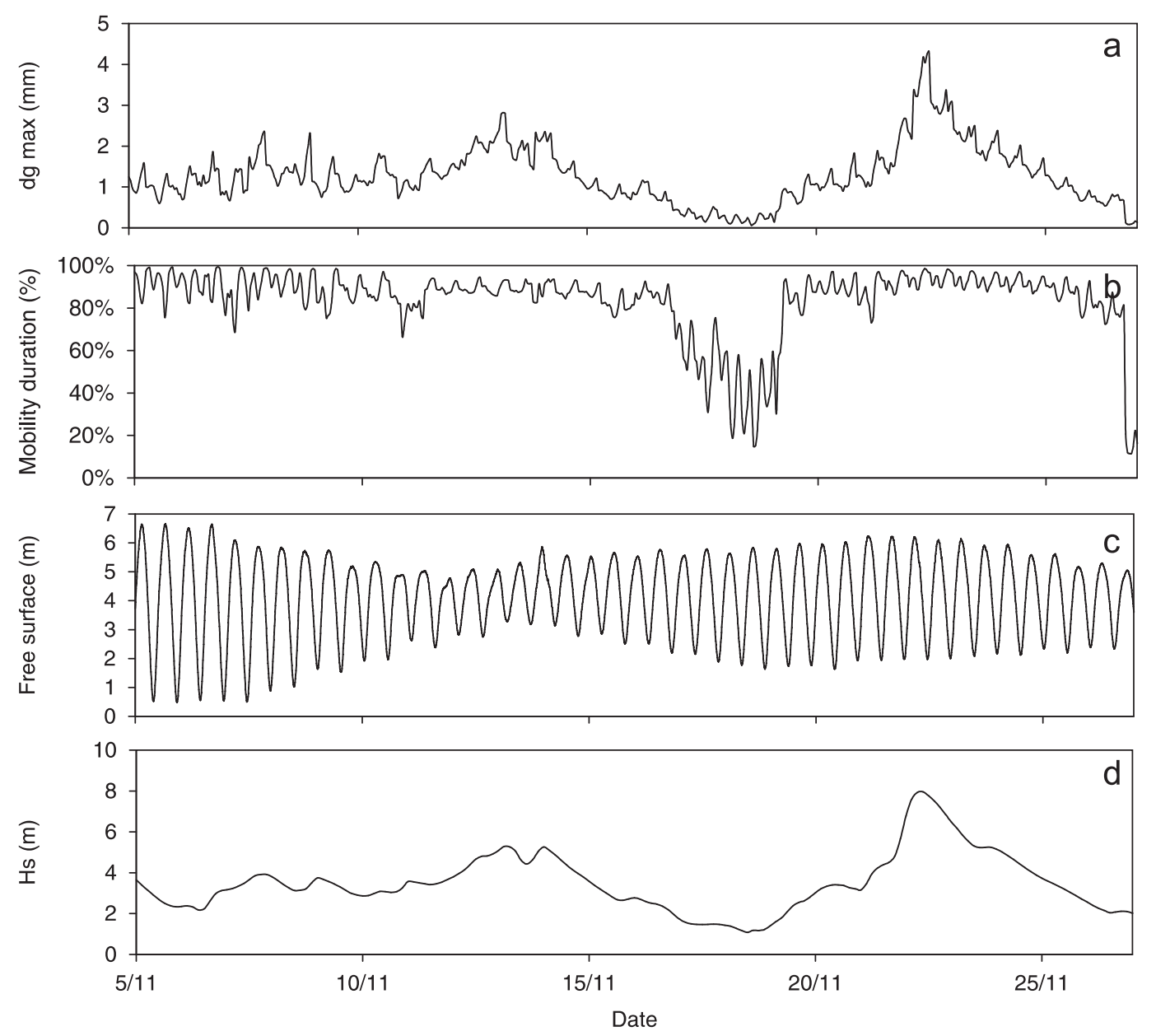

Fig. 9. (a) Maximum grain size potentially set in motion for $k s=0.6 \mathrm{~mm}$ (average value for all immersed grid points). (b) Relative duration of motion initiation for $0.2 \mathrm{~mm}$ grains throughout the campaign the 5-27 November 2002 period (average value for all immersed grid points). (c) Observed free surface level at La Rochelle Harbor (SONEL data). (d) NWW3 significant wave height at the node $\left(46^{\circ} \mathrm{N} ; 3.75^{\circ} \mathrm{W}\right)$.

average of all immersed grid nodes values. Fig. 9a shows the maximum grain size set in motion. Fig. 9b shows the duration percentage during which sands with a $0.2 \mathrm{~mm}$ diameter are set in motion. Figs. 9c and d show the corresponding forcing (free surface level at the La Rochelle harbour and significant wave height at the model offshore edge). Figs. 10a and $\mathrm{b}$ show a period (between 16 and 19 November) where maximum grain size decreases quite sharply and mobility duration as well. The mobility duration of $0.2 \mathrm{~mm}$ grains is less than $80 \%$ (Fig. 9b) as long as offshore wave height remains smaller than $2.5 \mathrm{~m}$ (Fig. $9 \mathrm{~d}$ ). The role of the free surface level is only that of a modulator. Thus, for all the study area, it could be assumed that mobility is quite weak for offshore wave heights of $2.5 \mathrm{~m}$, but that it increases considerably above this threshold. 

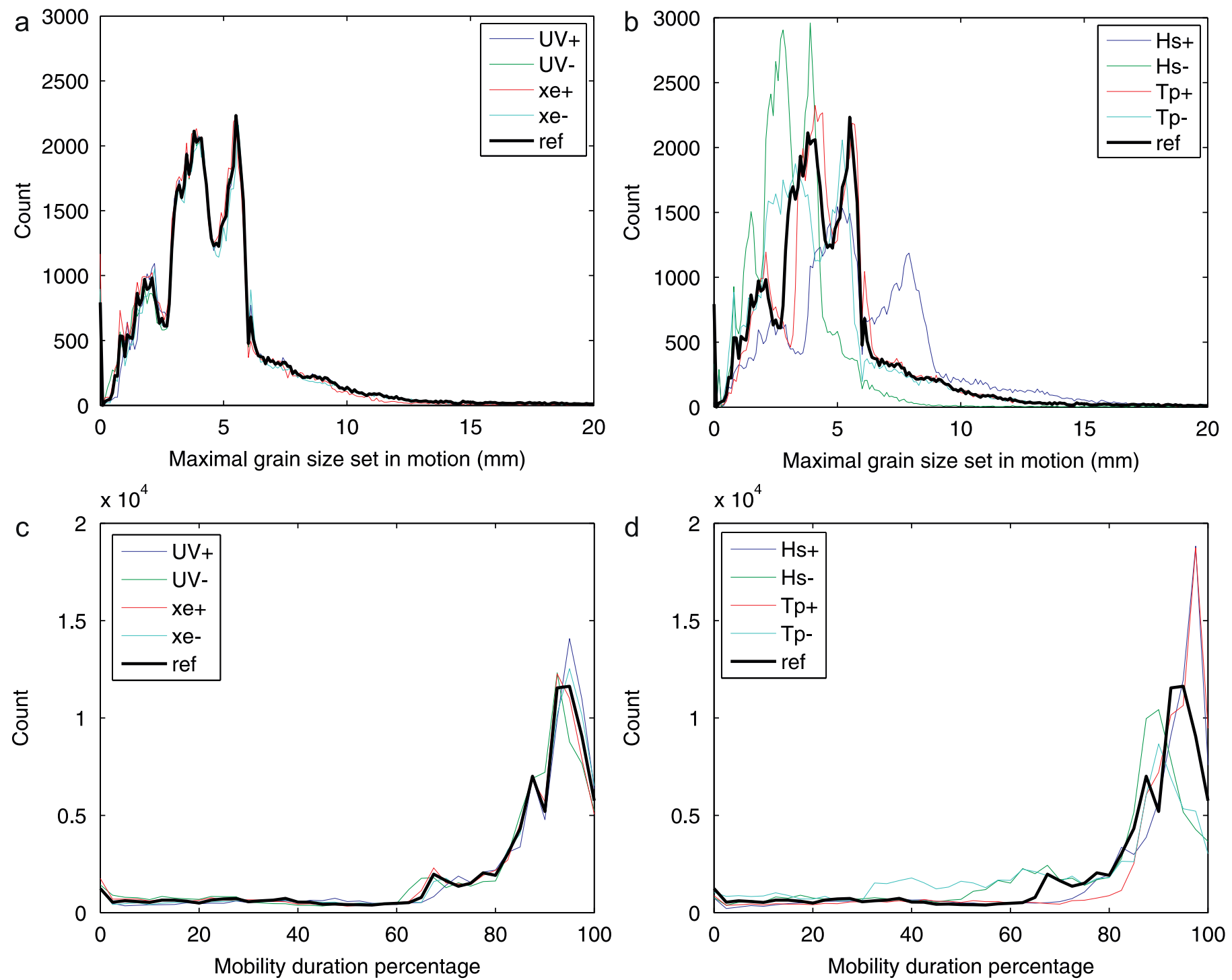

Fig. 10. Distribution of grid points among the (a, b) maximum grain size classes and (c, d) the mobility duration percentage classes for various hydrodynamic conditions (+ yields for hydrodynamic results $+20 \%$ and-yields for hydrodynamic results $-20 \%$ ).

\section{Sensitivity of the results}

\subsection{Hydrodynamic model quality sensitivity}

As shown in Section 4, hydrodynamic models are not perfect in terms of agreement with the observations. Errors can amount to some $10-30 \%$, depending on the chosen hydrodynamic parameter (significant wave height, peak period, free surface or current). Thus, in order to estimate the induced errors on the sediment mobility indicators (maximum grain size set in motion and mobility duration), computations are performed such that all the following parameters (significant wave height $H s$, peak period $T p$, $u$ and $v$ velocity components and free surface level $x e$ ) are set at $-20 \%$ and $+20 \%$ compared to the hydrodynamic model outputs.

Figs. 11a and $b$ show the distribution of maximum grain size set in motion during the study period, and the mobility duration for $0.2 \mathrm{~mm}$ grains corresponding to the different hydrodynamic conditions (e.g. hydrodynamic model results $\pm 20 \%$ ). This distribution corresponds to the count of grid nodes for different given ranges of value. The main modes range between 2 and $5 \mathrm{~mm}$. Fig. 10b shows that the maximum grain size set in motion is mainly influenced by errors in the wave characteristics (Hs, Tp). Decreasing $H s$ leads to a decrease in the mode of grain sizes of about $2-4 \mathrm{~mm}$, while increasing $H s$ produces a shift towards larger grain-size values. The influence of peak period is less pronounced. Errors in the current $(u v)$ and free surface $(x e)$ have a more minor influence on the results (Fig. 10a). Thus, whatever the errors in the hydrodynamic parameter are, the maximum grain sizes which could be set in motion over most of the study area range from about 2 to $5 \mathrm{~mm}$.

As to the mobility duration for $0.2 \mathrm{~mm}$ grains (Figs. 11c and d), the same conclusion can be drawn: the results are quite sensitive to wave errors but less so to current model errors. An increase in significant wave height or peak period leads to an increased mobility duration. However, for all the hydrodynamic configurations, most of the modes range between $90 \%$ and $100 \%$ of the campaign duration. Thus, whatever the errors in the hydrodynamic parameter, $0.2 \mathrm{~mm}$ grains would move during $90-100 \%$ of the study period throughout most of the area.

In summary, mobility results (duration and grain size) are more sensitive to wave characteristics errors than to current errors, but the modes remain almost the same for hydrodynamic 
a

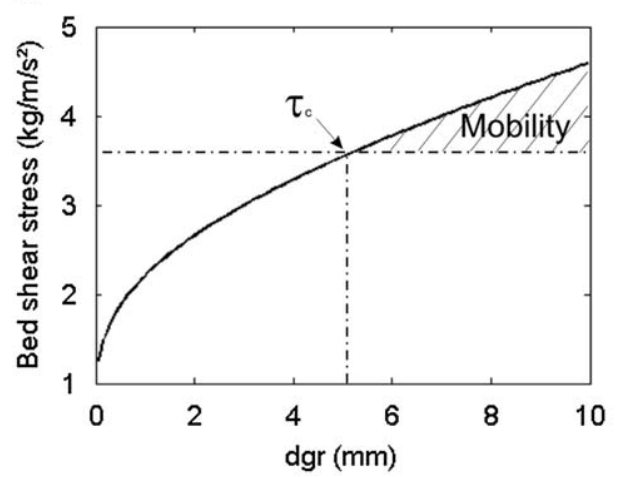

b

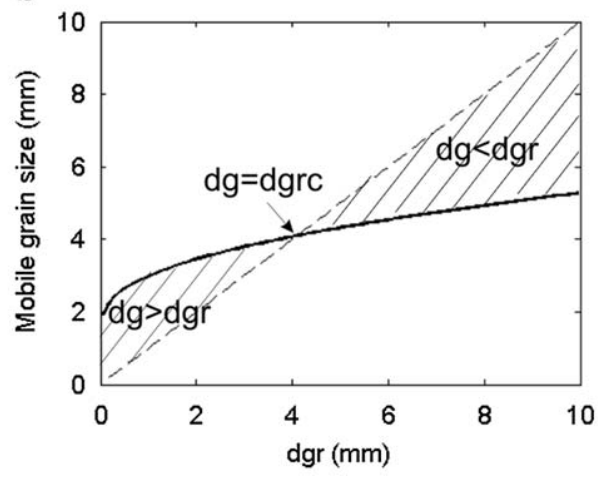

Fig. 11. Bed shear stress (a) and mobile grain size (b) versus bed grain size for the case: $H=23 \mathrm{~m}, U=1 \mathrm{~m} / \mathrm{s}, u b=0.5 \mathrm{~m} / \mathrm{s}, T p=9 \mathrm{~s}, H s=3 \mathrm{~m}$.
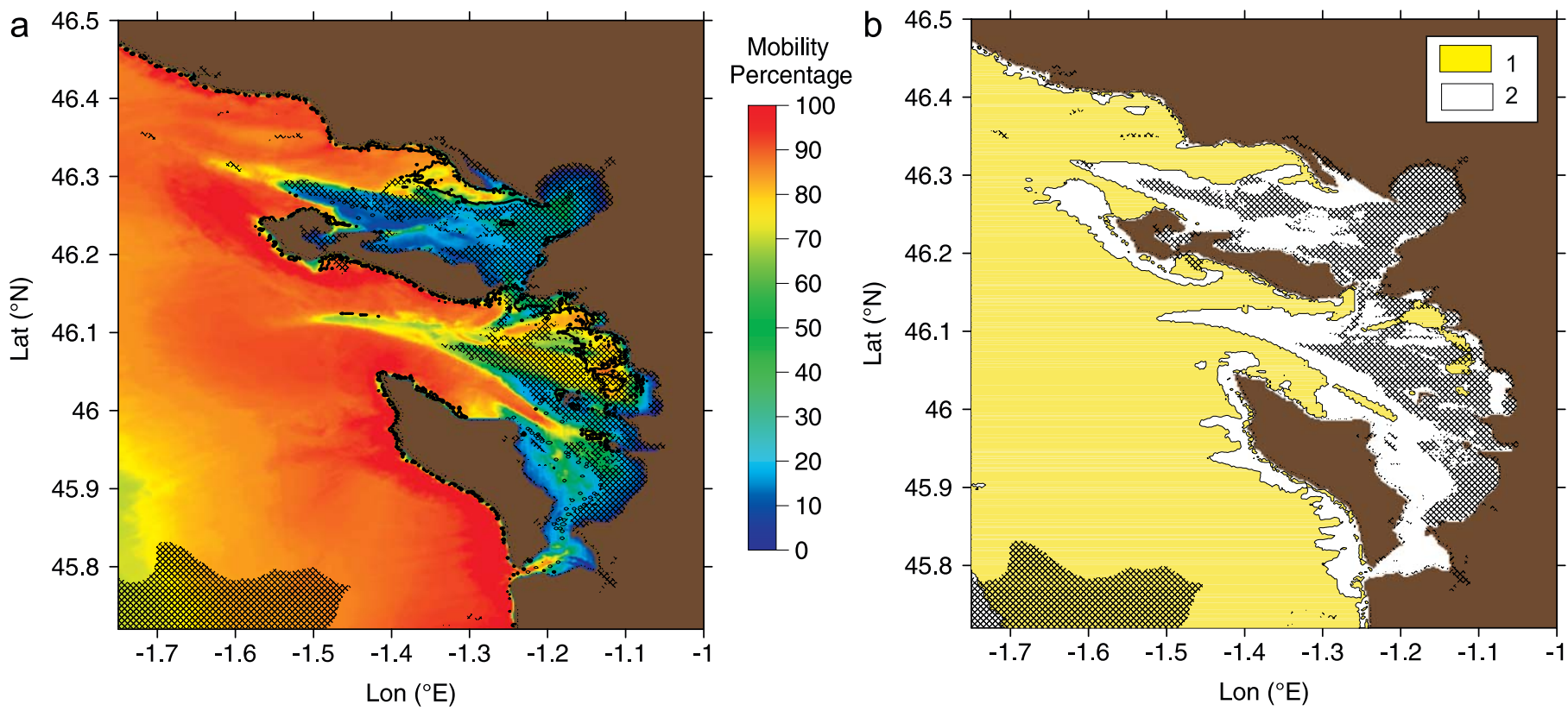

Fig. 12. (a) Relative duration of motion initiation of $0.2 \mathrm{~mm}$ grains during the $5-27$ November 2002 period under the action of currents and waves, taking into account ripple roughness, (b) area of predicted ripple on 5 November 2002 at 00:00 ( $H=2.2 \mathrm{~m}$ ) (1: prediction of ripples, 2: prediction of no ripples). Cohesive sediment areas (hatched) are excluded from this prediction.

variations (errors) of $\pm 20 \%$ for the present case. This is consistent with the results obtained in Section 5.1, where it is shown that waves play a dominant role in initiating sediment motion.

\subsection{The influence of bed roughness on the mobility of the $0.2 \mathrm{~mm}$ reference grain size}

A simple implementation of the equations giving the bed shear stress versus current, wave characteristics and bed roughness $k s$ makes it possible to study the sensitivity of the results to the bed roughness value $k s$. For instance, assuming a reference state of a water depth of $23 \mathrm{~m}$, a current velocity of $1 \mathrm{~m} / \mathrm{s}$, an orbital velocity of $0.5 \mathrm{~m} / \mathrm{s}$, a peak period of $9 \mathrm{~s}$, a significant wave height of $3 \mathrm{~m}$ and a bed roughness taking into account only the grain roughness related to the studied grain size, we obtain the variations of the bed shear stress versus the studied grain size (Fig. 11a). This shows that increasing the grain size Dgr ( $D g r$ is the grain size at the bed, controlling the skin bed roughness), corresponding directly to an increase in bed roughness $k s$, leads to an increase of the bed shear stress.
Therefore, the choice of bed roughness is essential to our sediment mobility analysis. The choice of $D g r$ and the assumption of considering bed roughness or grain roughness are both critical issues. In order to estimate the sensitivity of results (for the study area) to the bed roughness hypothesis, we investigate the influence of various bed roughness values on the mobility of the reference grain size of $0.2 \mathrm{~mm}$ :

- H1: Uniform grain bed roughness values of $0.3,3$ and $30 \mathrm{~mm}$ (corresponding respectively to grain sizes $\mathrm{Dgr}$ of $0.1,1$ and $10 \mathrm{~mm})$.

- H2: Non-uniform grain bed roughness based on a sedimentological map over the whole area (Fig. 1b). A grain size was assigned for each sedimentological class.

- H3: Non-uniform ripple-induced bed roughness. These ripples are generated by the waves using ripple predictor based on wave and sediment characteristics (Nielsen, 1981). This ripple computation is done for every node, when the skin friction exceeds the threshold of sediment motion on non-cohesive bed. Thus the ripple occurrence is non-stationary. Fig. 12a depicts the mobility duration throughout the campaign. These 
results are quite similar to those of the reference case, with a bed roughness related only to grains of $0.2 \mathrm{~mm}$ (Fig. 8a). It will be noted that, for instance for 5 November 2002 at 00:00, ripples would occur over most of the study area (Fig. 12b).

Fig. 13 depicts the histogram of the mobility duration for the five cases of $k s$ ( $\mathrm{H} 1, \mathrm{H} 2$ and $\mathrm{H} 3)$. This histogram represents the count of grid nodes for given ranges of value. For all of these, most of the area (e.g. grid points) is subject to a mobility duration of $0.2 \mathrm{~mm}$ grains exceeding $90 \%$. Mobility duration increases with the bed roughness (i.e., with increasing $D g r$ ). For $k s=0.3 \mathrm{~mm}$ (i.e., $D g r=0.1 \mathrm{~mm}$ ) and for the reference case $k s=0.6 \mathrm{~mm}$ (i.e., $D g r=0.2 \mathrm{~mm}$ ), the mode (highest peak) is $90 \%$, whereas for $k s$ due to larger Dgr, for non-homogeneous $k s$ and for the case of ripples on the seabed, it is $100 \%$. Thus, the results concerning the mobility duration of $0.2 \mathrm{~mm}$ sands are sensitive to the choice of

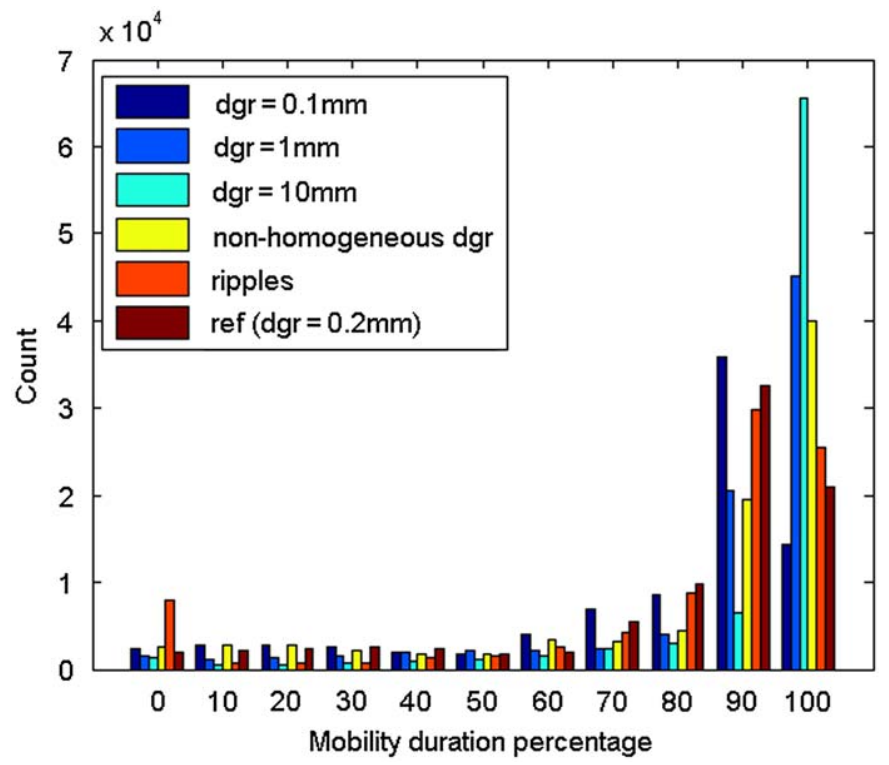

Fig. 13. Distribution of grid points among the mobility duration percentage classes. $0.2 \mathrm{~mm}$ grains for various grain roughnesses related to various values of $\mathrm{Dgr}$. bed roughness parameter, but in all cases the modes are greater or equal to $90 \%$ of the campaign duration. Accordingly, whatever the bed roughness parameter, the model predicts mobility for $0.2 \mathrm{~mm}$ sands over $90-100 \%$ of the time, for most of the study area.

\section{Discussion}

\subsection{Relevance of the sediment mobility indicators}

The methodology is shown to produce consistent results, also taking into account errors due to wave characteristics, for instance. Furthermore, considering that the choice of bed roughness $k s$ is a critical issue for the validity of results, a sensitivity analysis to different hypotheses has been necessary in order to ensure that results remain exploitable. In fact, the chosen methodology has proven to be efficient for obtaining sediment dynamics information and comparing relative wave and current contributions.

The results discussed in Sections 5 and 6 were based mainly on an indicator related to $0.2 \mathrm{~mm}$ reference grain-size mobility. We chose this value, physically representative of medium sand, in order to study sand mobility. However, having confirmed the validity of the methodology, it would be useful to ascertain whether the actual bed sediment could itself be set in motion. In order to get information on the potential of the seabed to be mobile, rather than typical $0.2 \mathrm{~mm}$ sand, we applied the same methodology to actual seabed grain sizes (Fig. 1b). Thus, the grain size considered for the mobility indicator $(D g)$ and grain roughness $k s$ (associated to $D g r$ ) are related to the seabed properties ( $D g=D g r=$ seabed grain size) and are no longer uniform. Fig. 14a shows the mobility duration percentage for every area. For reading convenience, mobility is divided into four classes ranging from no mobility to very high mobility. The results show that in most of the study area, mobility would exceed $75 \%$ of the study period, especially offshore of the two islands. We will note that the general mobility scheme is quite similar to the results obtained for grain size $D g=0.2 \mathrm{~mm}$.

In the present study, information was available regarding the sedimentological conditions. However, in many areas, such is not the case. Thus, in order to estimate the sensitivity of results (for the study area) to knowledge of the bed sediment, we examine
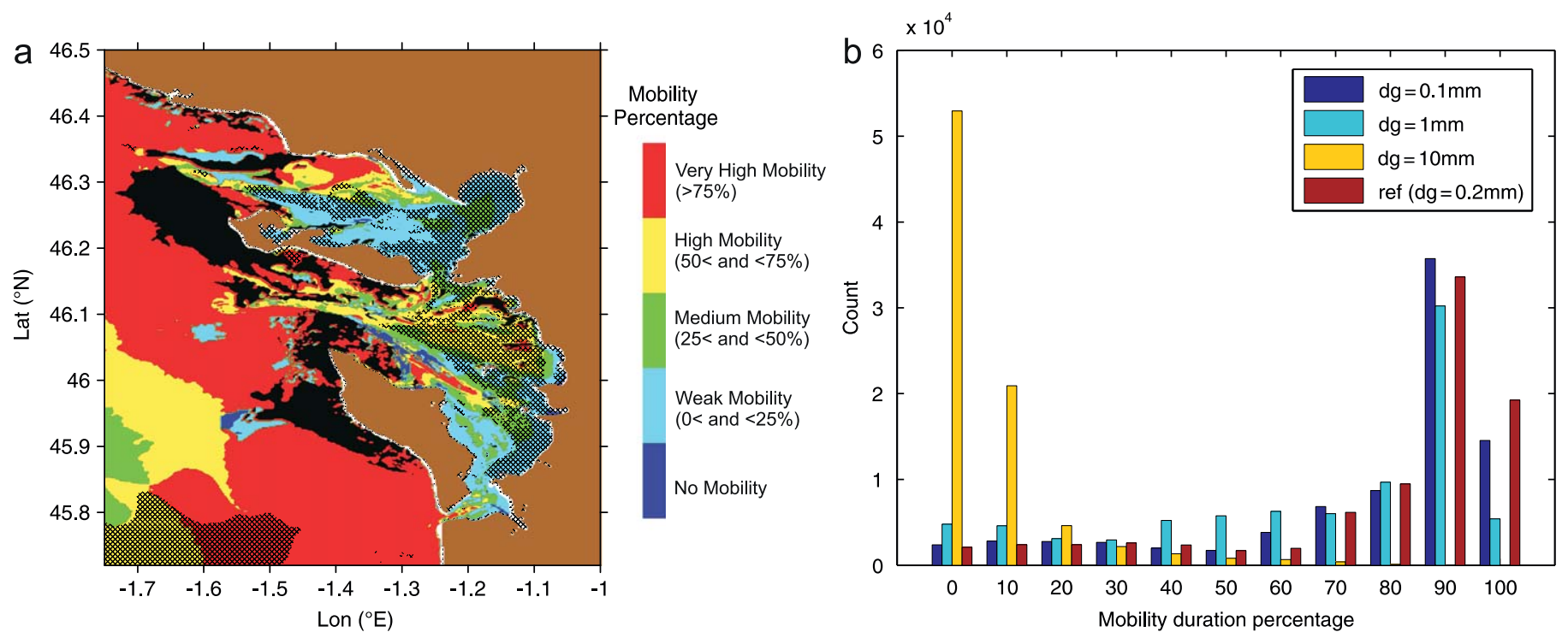

Fig. 14. (a) Relative duration of motion initiation for non-uniform grains (Fig. 1b) during the 5-27 November 2002 period. Cohesive sediment areas are hatched Rocky areas are indicated in black. (b) Mobility duration percentage of various grains, $D g$, for various grain roughnesses, such that $D g r=D g$. 
results assuming different superficial sediment characteristics: uniform grain sizes of $0.1,1$ and $10 \mathrm{~mm}$. Fig. $14 \mathrm{~b}$ shows the distribution of the mobility duration for the three values of $D g$ (with $D g r=D g$ ) and illustrates the sensitivity of the results to the choice of grain size. It shows that the larger the grain size is, the smaller the mobility percentage. The mode for the case of $D g=10 \mathrm{~mm}$ is equal to 0 , whereas it equals $90 \%$ for the cases $D g=1 \mathrm{~mm}, D g=0.1 \mathrm{~mm}$ and the reference case, $D g=0.2 \mathrm{~mm}$. Thus, as long as the chosen grain size falls within the diameter range corresponding to sand, the results remain quite similar. For much larger grains $(D g=10 \mathrm{~mm})$, results are substantially different. In view of the sedimentological data (Fig. 1b), this result is quite logical. Indeed, Fig. 1b shows that, over the domain concerned by the computations (the whole area except the cohesive sediment part), most of the area consists of sand.

Beyond this simple observation, we can demonstrate that the computations are not very sensitive to the choice of grain size provided, as long as this size falls within some qualitative range. Indeed, the simple use of Eqs. (1)-(6) giving the bed shear stress as a function of current, wave characteristics and grain bed roughness $k s$ also makes it possible to study the sensitivity of the results to the assumed bed sediment's grain size. Qualitatively, on the one hand, the larger the grain size and the grain roughness are, the larger the bed shear stress becomes (Section 6.2); but on the other hand, the larger this grain size is, the harder it is to set in motion. The issue of this sensitivity study lies in identifying when bed shear stress increase no longer compensates for sediment motion capacity decrease. Fig. 11b shows that above a given critical grain size ( $D g r c)$, the mobile grain size $D g$ will be smaller than the bed grain size used for grain roughness $(D g r)$. This critical grain size depends directly on hydrodynamic conditions. For the chosen case $(H=23 \mathrm{~m}, U=1 \mathrm{~m} / \mathrm{s}, u \mathrm{~b}=0.5 \mathrm{~m} / \mathrm{s}, T p=9 \mathrm{~s}, H \mathrm{~s}=3 \mathrm{~m})$, typical of the offshore area of the Pertuis Charentais region, this critical grain size is $4 \mathrm{~mm}$, meaning that only grain sizes smaller than $4 \mathrm{~mm}$ are set in motion. Thus, for hydrodynamic conditions like these, the results expressed in terms of mobility duration are not very sensitive to grain size if the grains are significantly smaller or larger than $4 \mathrm{~mm}$, whereas it must be more sensitive for areas having grain sizes in that order of magnitude. This means that in specific areas with sand or gravel sediment and subject to this type of hydrodynamic forcing, a qualitative knowledge of large-grain and sand-assimilated grain areas suffice to obtain a useful indicator of seabed mobility.

\subsection{Perspectives for sediment cover analysis}

In the literature, similar approaches, based on hydrodynamic data, have been set up, but with a different final purpose: whereas the present study intends to extract sediment mobility indicators, the other studies focus on the analysis of the existing sediment cover. For instance, in wave-dominated coastal environments, George and Hill (2008) used the idea of "inversing" hydrodynamic knowledge into sediment cover knowledge in order to identify water depth associated to sand-mud transition areas. Moreover, Dufois et al. (2008) compared bed shear stress calculation to existing sediment distribution in the Gulf of Lions shelf. Thus, it is worthwhile to discuss the relevance of the present study for such application, in the light of the differences between the objectives pursued. De facto, two main types of further investigation are identified for the use of the present method in any "sediment cover" type purpose: (1) overcome limits associated to the present case study's application constraints; (2) need for other types of indicators or expertise before interpretation.

First, the case study presented here is limited by different physical or numerical constraints. Indeed, the case study is based on a short period (one month), which is not representative of the hydrodynamic climate of the area. A complete climate analysis is thus needed in order to have an overview of sediment mobility statistics. Further more, the physical hypotheses used in the present study imply spatial limitations for the results validity: very shallow water areas (no wave breaking) and mudflats areas (non-cohesive sediment processes) are excluded from any interpretation.

Second, the indicators presented in this study are relevant for an understanding of sediment mobility; however they are not all completely sufficient for a sediment distribution analysis. Indeed, only offshore hydrodynamic forcing is considered here, without any acknowledgement of geomorphologic constraints, river sediment discharge, anthropic action, etc. Therefore, an interpretation of an hypothetic "bed shear stress atlas" would be constraint by an expert based analysis of the area's specific conditions, as it is proposed, for example, qualitatively, in Dufois et al. (2008). Finally, indicators used in the present study are relevant for sediment mobility analysis. It does not mean that they are all relevant for sediment cover analysis. For instance, the maximal grain size set in motion would not be useful for sediment cover analysis. Indeed, in areas where tides imply very shallow water for a rather short time (while it is being recovered or discovered by the tide), quite high grain sizes can be set in motion, whereas the mobility time remains very low (e.g. NorthEast of Oléron Island). Mobility time indicators are relevant, but could be interestingly completed by information on residual sediment fluxes.

Thus, even if the present study is relevant for sediment mobility investigations it would need further development for the interpretation of sediment cover: include more processes (cohesive sediment, residual sediment fluxes), study a longer period, interpret results knowing qualitative constraints (e.g. sediment sources, geomorphology). This would increase the relevance of the present study for sediment cover interpretation, but it would also increase the number of uncertainty sources.

\section{Conclusions}

The present study is based on modelling, under certain assumptions (uniform seabed, wave-current interaction not taken into account) and focuses on the initiation of sediment motion in a macro-tidal environment. It demonstrates the importance of waves in the dynamics of an internal continental shelf like the Pertuis Charentais area. Using validated wave and current models applied to the month of November 2002, we show that, during this period, grains with sizes of up to $10 \mathrm{~mm}$ could be set in motion, and that $0.2 \mathrm{~mm}$ grains on the western coast of the islands would be transported during $90 \%$ of the period. West of the islands, wave action appears to be dominant in the initiation of sediment motion, whereas east of them current action seems to dominate. Thus, there is still sediment mobility, at least an initiation of sediment motion, in quite deep areas with water depths up to $60 \mathrm{~m}$. This figure is much larger than what is sometimes assumed in practice.

The proposed methodology for basic sediment dynamics studies represents an effective means for comparing the relative influence of waves and currents on sedimentological processes. Besides, it is helpful to get information on surficial sediment mobility on the seabed, bearing in mind in particular that results continue to be exploitable even if we assume that hydrodynamic conditions may include errors of $\pm 20 \%$. This study demonstrates that the simple use of the maximum grain size set in motion can provide useful information through different indicators directly related to it. Furthermore, this methodology still remains relevant 
even for cases where only a qualitative sedimentological knowledge is available.

\section{Acknowledgements}

The authors would like to thank Ifremer (and especially Franck Dumas) for their permission to use the MARS code, as well as Sophie Lecacheux, Xavier Bertin and Pol Guennoc for fruitful discussions and contributions.

\section{References}

ANEMOC, Atlas Numérique d'Etats de Mer Océanique et Côtier - VERSION: 1.0.1, (c CETMEF/EDF R\&D-LNHE 2006/2007.

Barthe, X., Castaing, P., 1989. Étude théorique de l'action des courants de marée et des houles sur les sédiments du plateau continental du golfe de Gascogne. Oceanologica Acta 12 (4), 325-334

Bertin, X., Chaumillon, E., Sottolichio, A., Pedreros, R., 2005. Tidal inlet response to sediment infilling of the associated bay and possible implications of human activities: the Marennes-Oléron Bay and the Maumusson Inlet, France. Continental Shelf Research 25, 1115-1131.

Bertin, X., Castelle, B., Chaumillon, E., Butel, R., Quique, R., 2008. Longshore transport and inter-annual variability at a high energy dissipative beach: St Trojan, SW Oléron Island, France. Continental Shelf Research 28 Issues 10-11, 1316-1332.

Bidlot, J.R., 2008. Intercomparison of operational wave forecasting systems against buoy data, JCOMM Technical Report, WMO/TD.

Booij, N., Haagsma, I.J.G., Holthuijsen, L.H., Kieftenburg, A.T.M.M., Ris, R.C., van der Westuysen, A.J., Zijlema, M., 2004. Swan Cycle III version 40.41. User's Manual, 115 pp.

Chaumillon, E., Bertin, X., Falchetto, H., Allard, J., Weber, N., Walker, P., Pouvreau, N., Woppelmann, G., 2008. Multi time-scale evolution of a wide estuary linear sandbank, the Longe de Boyard, on the French Atlantic coast. Marine Geology 251, 209-223.

Drake, D.E., Cacchione, D.A., 1985. Seasonal variation in sediment transport on the Russian River shelf, California. Continental Shelf Research 4 (5), 495-514.

Dufois, F., Gareau, P., Le Hir, P., Forget, P., 2008. Wave- and current-induced bottom shear stress distribution in the Gulf of Lions. Continental Shelf Research 28 , 1920-1934.

Eidsvik, K.J., 2004. Some contributions to the uncertainty of sediment transport predictions. Continental Shelf Research 24, 739-754.
George, D.A., Hill, P.S., 2008. Wave climate, sediment supply and the depth of the sand-mud transition: a global survey. Marine Geology 254, 121-128.

Hall, P. Davies, A.M. 2002. Analysis of time-varying wind-induced currents in the North Channel of the Irish Sea, using empirical orthogonal functions and harmonic decomposition. Continental Shelf Research 22, 1269-1300.

Harris, C.K., Wiberg, P., 2002. Across-shelf sediment transport: interactions between suspended sediment and bed sediment. Journal of Geophysical Research 107 (C1), 3008

Idier, D., Pedreros, R., Oliveros, C., Sottolichio, A., Choppin, L., Bertin, X., 2006. Contributions respectives des courants et de la houle dans la mobilité sédimentaire d'une plateforme interne estuarienne. Exemple : le seuil interinsulaire, au large du Pertuis d'Antioche, France. C.R. Geosciences 338, 718-726.

Jones, J.E., Davies, A.M., 2006. Application of a finite element model (TELZEMAC) to computing the wind induced response iof the Irish Sea. Continental Shelf Research 26, 1519-1541.

Lazure, P., Dumas, F., 2008. An external-internal mode coupling for a 3D hydrodynamical model for applications at regional scale (MARS). Advances in Water Resources 31, 233-250.

Lyard, F., Lefèvre, F., Letellier, T., Francis, O., 2006. Modelling the global ocean tides: modern insights from FES2004. Ocean Dynamics doi:10.1007/s10236-0060086-X.

Nicolle, A., Karpytchev, M., 2007. Evidence of spatially variable friction from tidal amplification and asymmetry in the Pertuis Breton (France). Continental Shelf Research 27, 2346-2356.

Nielsen, P., 1981. Entrainment and distribution of different sand sizes. Journal of Geophysical Research 86 (C7), 6467-6472.

Paphitis, D., 2001. Sediment movement under unidirectional flows: an assessment of empirical threshold curves. Coastal Engineering 43 (3-4), 227-245.

Pawlowicz, R., Beardsley, B., Lentz, S., 2002. Classical tidal harmonic analysis including error estimates in MATLAB using T_TIDE. Computers and Geosciences 28, 929-937.

SHOM, Carte spéciale G n 6333G, 2000

Pinto, L., Fortunato, A.B., Freire, P., 2006. Sensitivity analysis of non-cohesive sediment transport formulae. Continental Shelf Research 26, 1826-1839.

Stanisière, J.Y., Dumas, F., Plus, M., Maurer, D., Robert, S., 2006. Caractérisation des composantes hydrodynamiques d'un système côtier semi-fermé : Le Bassin de Marennes-Oléron, Rapport Ifremer Ref DOP/LER.LER/PC/06.1059.

Swart, H., 1976. Predictive equations regarding coastal transports. In: Proceedings of the 15th Conference on Coastal Engineering, Honolulu, Hawaii.

Tolman, H.L., 2002. User manual and system documentation of WAVEWATCH-III version 2.22. Technical Note No. 222, Marine Modeling and Analysis Branch, NCEP, National Weather Service, NOAA, Department of Commerce, 139 pp.

Van Rijn, L.C., 1993. Principles of Sediment Transport in Rivers, Estuaries and Coastal Seas. Aqua Publications, Amsterdam, ISBN 90-800356-2-9. 